Nicotine in venous blood from smokers has been measured using gas chromatographic methods, ${ }^{12}$ but the results should be viewed with caution because of the presence of a nicotine-like substance, the nature of which is disputed. ${ }^{1-3}$ More recently venous nicotine levels have been measured by radioimmunoassay. ${ }^{13}$ The concentrations reported here are somewhat higher than those found in venous blood, and the rate of rise and fall in the arterial blood was also greater. The rapid increase in arterial nicotine concentrations was similar in all four smokers who inhaled, and the peak levels achieved were also similar. This suggests that smokers may adjust the way in which they smoke cigarettes in order to achieve a particular arterial nicotine concentration that is associated with a desirable psychological effect. ${ }^{14}$ The peak levels attained by the smokers who inhaled were of the same order as those found in animals, ${ }^{15}$ and these levels produce pharmacological effects on the central nervous system. $^{16}$ Our observations further support the concept that many smokers smoke to dose themselves with nicotine.

All the smokers who inhaled had an increase in their heart rate, which also occurred after intravenous doses of nicotine. As the nicotine levels fell so did the heart rate. Blood pressure also rose but was not so clearly related to the apparent dose of nicotine or the concentration in the blood. The response of heart rate to smoking a cigarette appears to be a simple way of classifying inhalers and non-inhalers.

The absorbed radioactivity was rapidly excreted into the urine after both inhalation and intravenous administration. Although the amounts of nicotine and cotinine were measured in the urine fractions, no firm conclusion was drawn from these data since neither urine flow nor urinary $\mathrm{pH}$ was controlled during the collection. ${ }^{17}$ Overall recoveries of radioactivity were poor in the non-smokers, which was almost certainly because the absorbed dose was overestimated.

Cotinine levels in blood rose continuously over the period of sampling after four to five minutes' delay, and by 60 minutes the levels usually exceeded those of nicotine. Cotinine levels have been measured by radioimmunoassay ${ }^{18}$ in plasma from smokers but the data are not strictly comparable to ours since the assays were performed on samples from people who had smoked more than one cigarette. In our subject 1 , cotinine was detectable after three puffs of smoke and blood levels increased rapidly thereafter. Interestingly, he had a short plasma antipyrine half life, indicating an active liver microsomal drug oxidising system. Urine excretion was also faster in this subject, which was consistent with the rapid production of more polar, less lipid-soluble metabolites.

These studies were supported by the Tobacco Research Council of Great Britain. We thank Mr J B Hopper, Mr P B Minty, and Miss $M$ Lillis for skilful technical help, and $\mathrm{Mr}$ B Emmett for preparing figs 1 and 2 .

\section{References}

1 Isaac, P F, and Rand, M H, Nature, 1972, 236, 308.

2 Russell, M A H, and Feyerabend, C, Lancet, 1975, 1, 179.

3 Houseman, $\mathrm{T} \mathrm{H}$, unpublished observations.

${ }^{4}$ Houseman, T H, and Heneage, E, Beiträge zur Tabakforschung, 1973, 7, 52.

${ }^{5}$ Houseman, T H, Beiträge zur Tabakforschung, 1973, 7, 142.

6 Houseman, T H, and Hopper, J B, Tobacco Science, 1974, 18, 160.

7 Turner, D M, Biochemical fournal, 1969, 115, 889.

${ }^{8}$ Evans, E A, Tritium and its Compounds, p 221. London, Butterworths, 1961.

9 Commins, B T, and Lawther, P J, British fournal of Industrial Medicine, 1965, 22, 139.

10 Armitage, A K, et al, Quarterly fournal of Experimental Physiology, 1974, $59,43$.

11 Bowman, E R, Turnbull, L B, and McKennis, H, jun, fournal of Pharmacology and Experimental Therapeutics, 1959, 127, 92.

12 Papadopoulos, N M, and Kintzios, J A, Fournal of Pharmacology, 1963, $140,269$.

${ }^{13}$ Harris, C F, et al, Clinical Pharmacology and Therapeutics, 1974, 16, 1083.

14 Ashton, H, and Watson, D W, British Medical fournal, 1970, 2, 679.

15 Turner, D M, British fournal of Pharmacology, 1971, 41, 521.

16 Armitage, A K, Hall, G H, and Morrison, C F, Nature, 1968, 217, 331.

17 Beckett, A H, Gorrod, J W, and Jenner, P, fournal of Pharmacy and Pharmacology, 1971, 23, 55S.

18 Langone, J J, Gjika, H B, and Van Vunakis, H, Biochemistry, 1973, 12, 5025.

\title{
Plasma renin activity and aldosterone concentration in children
}

\author{
M J DILLON, JENNIFER M RYNESS
}

British Medical fournal, 1975, 4, 316-319

\begin{abstract}
Summary
Using semi-micro methods, plasma renin activity (PRA) and plasma aldosterone concentration (PA) were measured concurrently in 79 healthy children aged 1 month to 15 years to establish a reference range. PRA and PA varied inversely with age. Eleven children with renal hypertension had higher PRA and PA than age-matched controls. In contrast, PRA was much greater in 38 salinedepleted children. PA was not uniformly increased in this group and was within the normal range in children with adrenal diseases compared with the high values seen in
\end{abstract}

Department of Chemical Pathology, Institute of Child Health and Renal Unit, Hospital for Sick Children, London WC1

M J DILLON, MRCP, research fellow (present appointment: consultant physician, Hospital for Sick Children, London WC1)

JENNIFER M RYNESS, BSC, biochemist other salt-wasting states. The findings emphasise the need to relate data from patients to age-matched control values before attempting interpretation and suggest that sodium depletion is a more potent stimulator of renin-aldosterone release than renovascular disease or renal scarring in children. Plasma renin-aldosterone profiles were also valuable in discriminating between renal and adrenal causes of salt loss in childhood.

\section{Introduction}

The renin-angiotensin-aldosterone system has been investigated extensively in adults, but relatively little information has been reported in children, partly because of the large quantities of blood hitherto needed for measuring the system's components and the sampling difficulties encountered in young children. Studies in animals have shown increased activity of the reninangiotensin-aldosterone system in the newborn of various species. ${ }^{1-5}$ Early studies in the human provided inconclusive but suggestive evidence of higher plasma renin levels in children than in adults, ${ }^{6-12}$ and in 1972 Kotchen et $a l^{13}$ and Hayduk 
et $a l^{14}$ reported, respectively, increased plasma renin activity (PRA) and increased renin concentrations (PRC) in newborn infants. In the same year Krause $e t a l^{15}$ showed a significant negative correlation between PRC and body surface area in children, and, more recently, significantly higher PRA has been found in adolescents than in adults. ${ }^{16}$ Increased plasma aldosterone concentrations (PA) have also been reported in the human newborn infant ${ }^{17^{-21}}$ and during the first year of life. ${ }^{22}$

These earlier studies have, however, with one exception ${ }^{21}$ reported only the renin or the plasma aldosterone level. We have developed semi-micro methods that have enabled us to measure PRA and PA concurrently in healthy children from infancy to adolescence. Reference ranges were established and related to findings in children with renal hypertension or salt-wasting states. A preliminary account of this work has been given. ${ }^{23}$

\section{Methods}

PRA was measured in $0.25 \mathrm{ml}$ of plasma by the radioimmunoassay of generated angiotensin I (AI). ${ }^{24} \mathrm{PA}$ was measured in 0.25 to $1.0 \mathrm{ml}$ plasma using a method based on that of Mayes et al. ${ }^{25}$ The antibody to aldosterone $18 \cdot 21$ hemidisuccinate bovine serum albumin complex ${ }^{26}$ was used at a final dilution of 1 in 500000 . Within-assay precision as represented by the coefficient of variation of duplicates ranging through the standard curve was less than $10 \%$. Between-assay variation was less than $15 \%$. Recovery of $139-555 \mathrm{fmol}(50-200 \mathrm{pg})$ of aldosterone added to water was $90-110 \%$. Sensitivity was $9.9 \mathrm{fmol}(3.6 \mathrm{pg})$ assay tube. Venous blood samples were taken between 9 am and midday, and the subjects were supine for two hours before sampling. Random urine specimens were collected on the morning of the test for measurement of sodium and creatinine concentrations. From the sodium:creatinine concentration ratio the subject's sodium excretion and hence, turnover in a steady state, was calculated in $\mathrm{mmol} \mathrm{kg}$ body weight ${ }^{-1}$ day $^{-1}$ $(\mathrm{mEq} / \mathrm{kg}$ body weight/day), assuming a urinary creatinine excretion of $53 \mu \mathrm{mol} \mathrm{kg}$ body weight ${ }^{-1} 24 \mathrm{~h}^{-1}(15 \mathrm{mg} / \mathrm{kg} / 24 \mathrm{~h})$.

The control group of children consisted of 79 patients aged 1 month to 15 years who were in hospital for minor disorders. They had no evidence of circulatory or renal disease or disorder of acid base or electrolyte metabolism. They were on free diets and all required venepuncture during the course of their investigations. Nine healthy adult control subjects aged 24 to 39 years were also studied.

Eleven children, aged 5 to 15 years, with hypertension secondary to renovascular disease or renal scarring were investigated. These children were not suffering from renal failure nor were they receiving hypotensive treatment. An 18-month-old hypertensive child with complex renovascular disease was considered separately as he was much younger than the others.

Thirty-eight children, aged 1 week to 15 years, had disease causing saline depletion. Eight had acute gastrointestinal salt and water losses, 19 had congenital adrenal hyperplasia (CAH) or Addison's disease, and most of the remaining 11 had renal tubular disease associated with salt wastage. Of the salt-depleted children only one, an infant of 8 days with $\mathrm{CAH}$, was under 1 month of age.

Because paired specimens were not available from all children a few had only their PRA measured.

\section{Results}

The table shows the geometric mean and observed range of PRA and PA in supine control subjects, as well as their geometric mean sodium excretion. The data from the control subjects were analysed to study the relation between PRA, PA, age, and sodium excretion.
A multiple regression analysis was undertaken on logarithmically transformed data using PRA as the dependent variable. A significant negative correlation was found between PRA and age $(P<0.0001)$; (fig 1). The partial negative correlation of PRA, already regressed on age, with the remaining variables was significant only for sodium excretion $(P<0 \cdot 01)$. The residuals from this regression analysis using logarithms were apparently normally distributed.

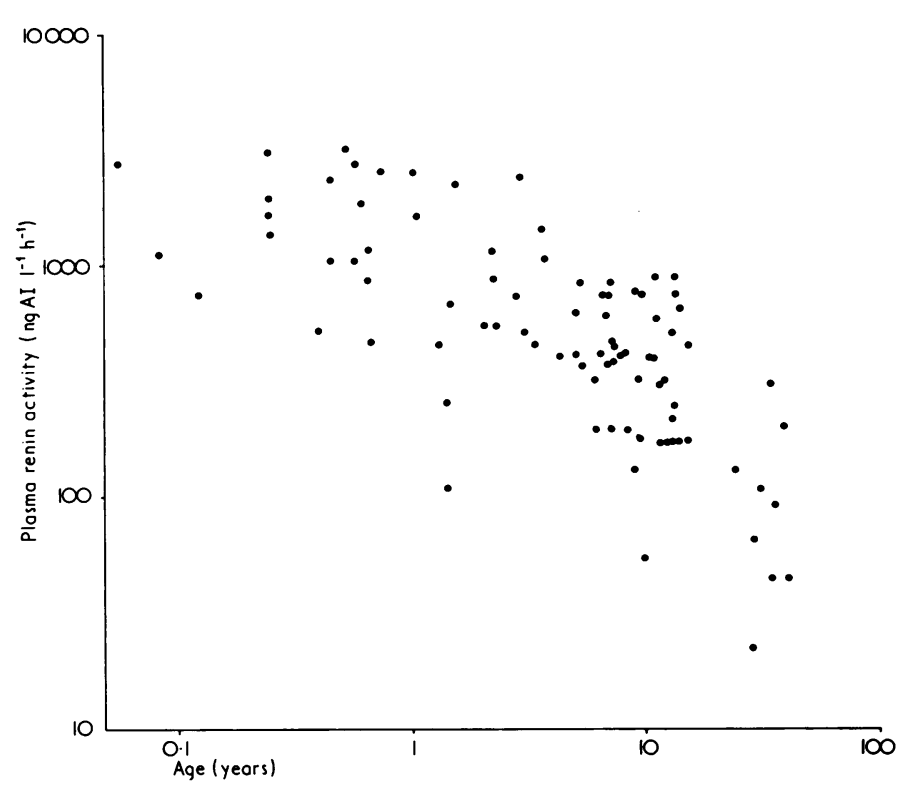

FIG 1-Plasma renin activity according to age in control subjects.

PA correlated negatively with age $(P<0.005)($ fig 2$)$ and positively with PRA but did not correlate significantly with sodium excretion. The partial correlation of PA with PRA was insignificant once age had been taken into account $(r=-0.05)$. Thus the correlation between levels of PRA and PA seemed to be almost entirely dependent on age.

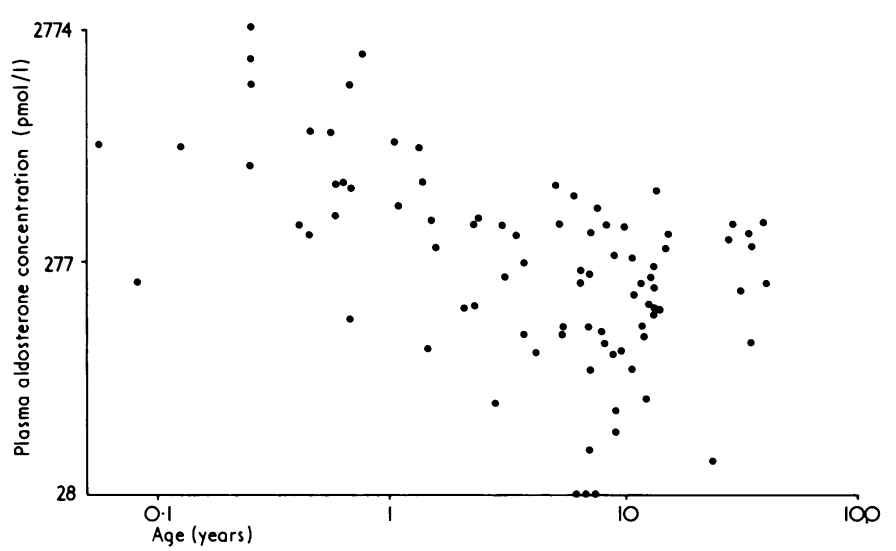

FIG 2-Plasma aldosterone concentrations according to age in control subjects. Conversion: SI to traditional units-Aldosterone: $1 \mathrm{pmol} / 1 \approx 0.036$ $\mathrm{ng} / 100 \mathrm{ml}$.

Geometric mean and observed range of plasma renin activity and plasma aldosterone concentration in supine controls

\begin{tabular}{|c|c|c|c|c|c|c|c|}
\hline \multirow{2}{*}{$\begin{array}{c}\text { Age } \\
\text { (years) }\end{array}$} & \multirow{2}{*}{$\begin{array}{c}\text { No of } \\
\text { subjects }\end{array}$} & \multirow{2}{*}{$\begin{array}{c}\text { Mean sodium } \\
\text { excretion } \\
\left(\mathrm{mmol} \mathrm{kg}^{-1} \text { day }^{-1}\right)\end{array}$} & \multicolumn{2}{|c|}{$\begin{array}{l}\text { Supine plasma renin activity } \\
\left(\mathrm{ng} \mathrm{AI} 1^{-1} \mathrm{~h}^{-1}\right)\end{array}$} & \multicolumn{3}{|c|}{$\begin{array}{l}\text { Supine plasma aldosterone concentration } \\
\qquad(\mathrm{pmol} / \mathrm{l})\end{array}$} \\
\hline & & & Mean & Observed range & Mean & \multicolumn{2}{|c|}{ Observed range } \\
\hline $\begin{array}{c}<1 \\
1-4 \\
5-9 \\
10-15 \\
\text { Adult }\end{array}$ & $\begin{array}{r}18 \\
18 \\
24 \\
19 \\
9\end{array}$ & $\begin{array}{l}1 \cdot 2 \\
3 \cdot 8 \\
2 \cdot 5 \\
2 \cdot 5 \\
2 \cdot 1\end{array}$ & $\begin{array}{r}1459 \\
757 \\
417 \\
321 \\
85\end{array}$ & $\begin{array}{r}472-3130 \\
110-2610 \\
131-834 \\
55-899 \\
22-311\end{array}$ & $\begin{array}{l}788 \\
294 \\
147 \\
211 \\
230\end{array}$ & $\begin{array}{r}164 \\
69 \\
28 \\
72 \\
39\end{array}$ & $\begin{array}{r}2929 \\
946 \\
616 \\
577 \\
422\end{array}$ \\
\hline
\end{tabular}


Mean PRA and PA in the children aged 5-15 years with hypertension

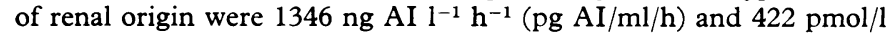
$(15.2 \mathrm{ng} / 100 \mathrm{ml}$ ) respectively (figs 3 and 4$)$. By $t$ testing on logtransformed data these values were found to be significantly greater than the mean values of $371 \mathrm{ng} \mathrm{AI} 1^{-1} \mathrm{~h}^{-1}$ and $172 \mathrm{pmol} / 1(6 \cdot 2 \mathrm{ng} / 100 \mathrm{ml})$ found in the age-matched controls $(P<0.0005$ for PRA and $P<0.0025$ for PA). PRA and PA in the 18-month-old hypertensive child excluded

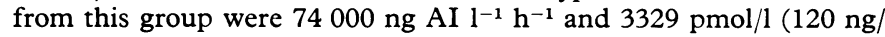
$100 \mathrm{ml}$ ) respectively.

PRA values in children with saline depletion were much greater,

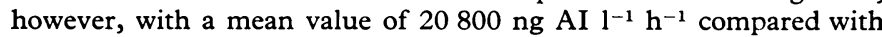
$596 \mathrm{ng} \mathrm{AI} \mathrm{l}^{-1} \mathrm{~h}^{-1}$ for age-matched controls $(\mathrm{P}<0.0005$; fig 3$)$. There were no significant differences between mean PRA values for children with acute gastrointestinal salt loss, adrenal insufficiency, and chronic renal tubular disease. The difference between mean PRA values in age-matched saline depleted children and hypertensive children was highly significant $(P<0.0005)$.

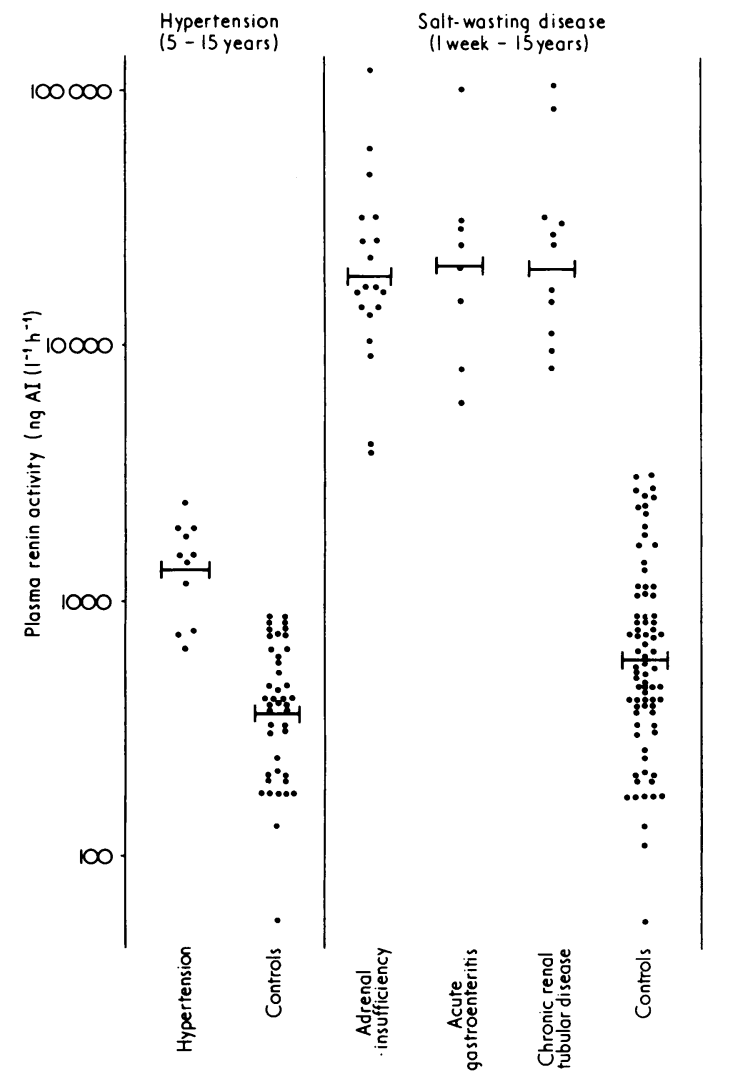

FIG 3-Plasma renin activity in children with hypertension and those with salt-wasting diseases compared with control values.

Fig 4 shows that PA was not uniformly increased in the salinedepleted patients, in children with adrenal disorders the values were within the normal range, in contrast to the high values seen in the other salt wasters. Mean PA in children with CAH or Addison's disease was $316 \mathrm{pmol} / 1(11.4 \mathrm{ng} / 100 \mathrm{ml})$ compared with the agematched control group mean of $275 \mathrm{pmol} / \mathrm{l}(9.9 \mathrm{ng} / 100 \mathrm{ml})$, whereas the mean PA for children with acute gastrointestinal or chronic renal tubular salt-losing disease was $1939 \mathrm{pmol} / 1 \quad(69.9 \mathrm{ng} / 100 \mathrm{ml})$ $(P<0.0005)$. There was no significant difference between PA in the acute or chronic saline-depleted groups, but PA was significantly greater in these children than in age-matched hypertensive children $(\mathrm{P}<0.0005)$.

\section{Discussion}

The demonstration that both PRA and PA vary inversely with age in infants and children has important implications. It emphasises the need to relate pathological data to age-matched control values before attempting interpretation. Sassard et al have also shown a similar inverse relationship between PRA and

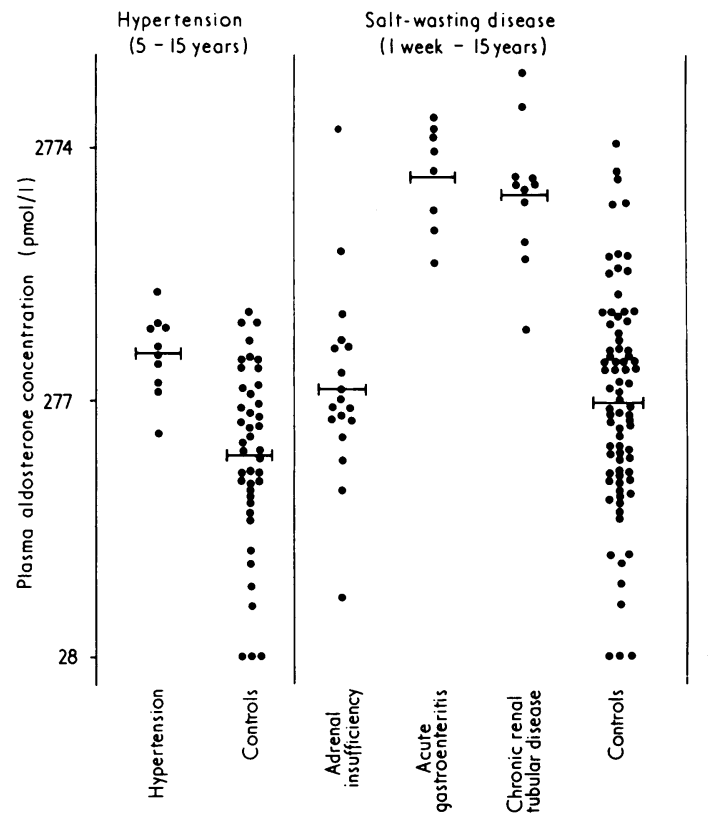

FIG 4-Plasma aldosterone concentrations in children with hypertension and those with salt-wasting diseases compared with control values.

age in children from infancy to adolescence. ${ }^{27}$ The reason for the higher plasma concentrations of renin and aldosterone in young children, however, is by no means established. A variety of possible explanations have been considered by several workers. ${ }^{13} 1520-2228$

Sodium deprivation enhances renin secretion and it is established that PRA and PA should be interpreted in relation to sodium turnover ${ }^{29}{ }^{30}$ or total exchangeable sodium. ${ }^{31}$ In view of this, infants and young children may possibly exist on a lower sodium intake and level of extracellular fluid expansion than older children and adults. It is of interest that we have observed suppression of PRA below the adult mean value in an infant injudiciously overloaded with salt and water. ${ }^{32}$ It is difficult, however, to compare rates of sodium turnover in infants and adults because of their widely ranging body sizes. We chose to assess sodium turnover related to body weight from the sodium creatinine concentration ratio in a random morning urine specimen, assuming a urinary creatinine excretion of $53 \mu \mathrm{mol} / \mathrm{kg}$ body weight ${ }^{-1} 24 \mathrm{~h}^{-1}(15 \mathrm{mg} / \mathrm{kg} /$ day $)$. This approximation is the source of slight error since it is known that infants excrete less creatinine per unit body weight than older children and adults. ${ }^{33}$ Our data suggest that in the control infants sodium turnover expressed as mmol Kg body weight ${ }^{-1}$ day $^{-1}$ was less than in older children or adults. In the 1-4 year age group, however, sodium turnover was greater, yet PRA was nine times higher than in the adults. Low sodium intake, therefore, cannot be the sole explanation of the increased PRA in young children, and analysis of our data showed that the levels of PRA and PA were almost entirely dependent on age and only marginally attributable to differences in sodium intake.

There are two physiological characteristics of the infant kidney that may be relevant to the high PRA and PA.

Firstly, renal cortical perfusion is substantially less in the young kidney owing to increased renal vascular resistance. ${ }^{34}$ Secondly, proximal tubular function is relatively less efficient in the immature kidney, ${ }^{35}$ and an increased delivery of filtered sodium to the macula densa area may stimulate renin release ${ }^{36}$ and so indirectly enhance distal sodium reabsorption. The infant and young child may thus be more dependent on renin-aldosterone stimulated distal tubular sodium reabsorption for the maintenance of salt balance, ${ }^{37}$ which may account for the greater liability of the infant with CAH to salt-losing crises.

The inverse relationship with age extends into the neonatal period; in a preliminary study values of PRA and PA in cord blood and on the 6th day of life were, respectively, three and one and a half times the 
mean values found in infants over the age of 1 month. ${ }^{38}$ These figures accord with the findings of others, particularly those in Pipkin and Smales's study of plasma angiotensin II levels in the newborn. ${ }^{39}$

The demonstration in children with hypertension secondary to renal vascular anomalies or renal scarring of higher PRA levels than in healthy children of equivalent age contrasts with some findings in adults. ${ }^{40}$ Since the numbers were comparatively small, however, it remains to be seen whether the use of peripheral PRA values will prove to be of greater diagnostic value in the investigation of hypertension in children than in adults.

In contrast to the findings in hypertension of renal origin, the levels of PRA and PA in non-adrenal causes of salt-wasting were much higher. This did not seem to be due to excess renal tubular salt loss per se, since virtually identical data were obtained from children with gastrointestinal disease. Sodium depletion, therefore, seems to be a more potent stimulator of renin-aldosterone release than renovascular disease or renal scarring in children.

The relation between PRA and PA in people in whom there is no reason to postulate an abnormality of aldosterone responsiveness to renin-angiotensin stimulation (fig 5) permits us to identify conditions in which inappropriate responses occur. For example, in aldosterone deficiency states PA was within the normal range for age but inappropriately low in relation to the simultaneously determined PRA. Conversely, in Conn's syndrome, and in a child with congenital absence of kidneys, PA was raised despite low PRA values. These observations have greatly facilitated the investigation of salt-wasting disease in infancy and childhood.

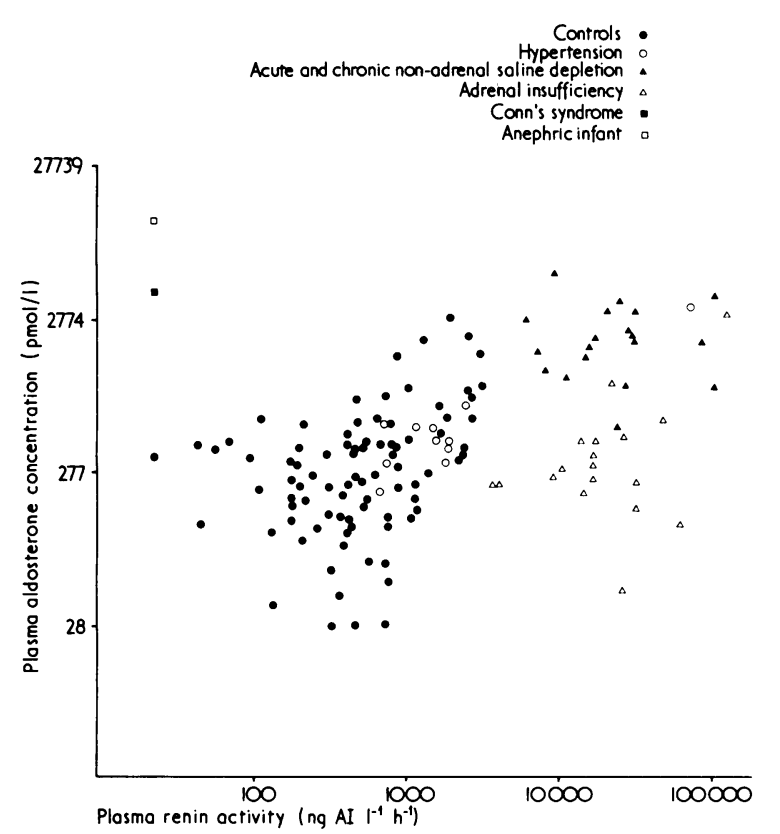

FIG 5-Relation between plasma renin activity and aldosterone concentrations in patients and controls.

The use of the plasma renin-aldosterone profile allows us to discriminate between renal and adrenal causes of salt loss and is particularly useful in the evaluation of Addison's disease, $\mathrm{CAH}$, and other biosynthetic defects of aldosterone.

We thank Professor Barbara E Clayton and Dr T M Barratt for their support and encouragement, Mrs V Shah for skilled technical help, Dr A D Patrick, Dr R W H Edwards, and Mrs S M Atherden for their help, and the physicians and surgeons of the Hospital for Sick Children and paediatricians in many other hospitals for permission to study patients under their care. We are indebted to Mrs Hilary E Tillett, Epidemiological Research Laboratory (Public Health Laboratory Service), London, for the multiple regression analysis of the control data, and to Professor V H T James and his department, St Mary's Hospital Medical School, London, for help in setting up the plasma aldosterone assay, and to Professor J F Tait, Middlesex Hospital Medical School, London, for donating the antibody to aldosterone.

MJD holds the Alan Moncrieff Educational Research Fellowship supported by the Buttle Trust and financial support was provided by the Joint Research Board of the Hospitals for Sick Children and the Institute of Child Health, London.

Requests for reprints should be addressed to $\operatorname{Dr} M \mathrm{~J}$ Dillon, Institute of Child Health, 30 Guilford Street, London, WC1N 1EH.

\section{References}

1 Pipkin, F B, Mott, J C, and Roberton, N R C, fournal of Physiology, 1971, $218,385$.

${ }^{2}$ Granger, P, et al, Canadian fournal of Physiology and Pharmacology, 1971, 49, 134.

${ }^{3}$ Pipkin, F B, D Phil thesis, University of Oxford, 1973.

${ }^{4}$ Malinowska, K W, and Nathanielsz, P W, fournal of Physiology, 1974, 236, 83.

${ }^{5}$ Pipkin, F B, et al, fournal of Physiology, 1974, 241, 575.

${ }^{6}$ Godard, C, et al, Pediatrics, 1968, 41, 883.

7 Imai, M, Igarashi, Y, and Sokabe, H, Pediatrics, 1968, 41, 897.

${ }^{8}$ Geelhoed, G W, and Vander, A J, fournal of Clinical Endocrinology, 1968, 28,412 .

9 Amsterdam, E A, et al, American fournal of Cardiology, 1969, 23, 396.

10 Kokot, F, and Cekanski, A, Zentralblatt fur Gynakologie, 1970, 92, 280.

11 Londe, S, et al, Fournal of Pediatrics, 1971, 78, 569.

12 Voûte, P A, jun, van der Meer, J, and Staugaard-Kloosterziel, W, Acta Endocrinologica, 1971, 67, 197

13 Kotchen, T A, et al, fournal of Pediatrics, 1972, 80, 938.

14 Hayduk, K, et al, Experientia, 1972, 28, 1489

15 Krause, D K, Schillmoller, U, and Hayduk, K, German Medicine, 1972, $2,103$.

16 Goldberg, S, et al, Pediatrics, 1974, 54, 596.

17 Bayard, F, et al, fournal of Clinical Investigation, 1970, 49, 1389.

18 Beitins, I Z, et al, fournal of Clinical Investigation, 1972, 51, 386.

19 Siegel, S R, Fisher, D A, and Oh, W, Fournal of Pediatrics, 1973, 83, 854.

20 Siegel, S R, Fisher, D A, and Oh, W, Pediatrics, 1974, 53, 410.

${ }^{21}$ Katz, F H, Beck, P, and Makowski, E L, American fournal of Obstetrics and Gynecology, 1974, 118, 51.

${ }^{22}$ Kowarski, A, Katz, H, and Migeon, C J, fournal of Clinical Endocrinology and Metabolism, 1974, 38, 489.

${ }^{23}$ Dillon, M J, and Ryness, J, Archives of Disease in Childhood, 1974, 49, 823.

24 Dillon, M J, Fournal of Clinical Pathology, 28, 625.

${ }^{25}$ Mayes, D, et al, fournal of Clinical Endocrinology and Metabolism, 1970, 30, 682 .

${ }^{26}$ Haning, R, et al, Steroids, 1972, 20, 73.

27 Sassard, J, et al, fournal of Clinical Endocrinology and Metabolism, 1975, $40,524$.

${ }^{28}$ Mott, J C, British Medical Bulletin, 1975, 31, 44.

${ }^{29}$ Laragh, J H, et al, American fournal of Medicine, 1972, 52, 633.

${ }^{30}$ Bühler, F R, et al, American fournal of Cardiology, 1973, 32, 554.

31 Davies, D L, et al., Lancet, 1973, 1, 683.

32 Whitelaw, A G L, Dillon, M J, and Tripp, J H, Archives of Disease in Childhood, 1975, 50, 400.

${ }^{33}$ Graystone, J E, in Human Growth, ed D B Cheek, p 182, Philadelphia, Lea and Febiger, 1968.

${ }^{34}$ Gruskin, A B, Edelmann, C M, and Yuan, S, Pediatric Research; 1970, $4,7$.

${ }^{35}$ Edelmann, C M, and Spitzer, A, Fournal of Pediatrics, 1969, 75, 509.

${ }^{36}$ Thurau, K W C, et al, Circulation Research, 1972, 30-31, suppl 2, p 182.

${ }^{37}$ Dillon, M J, Archives of Disease in Childhood, 1974, 49, 831

${ }^{38}$ Dillon, $M \mathrm{~J}$, et al, unpublished.

${ }^{39}$ Pipkin, F B, and Smales, O R C, Archives of Disease in Childhood, 1975, 50, 330 .

40 Brown, J J, et al, British Medical fournal, 1965, 2, 1215. 